\title{
DESIGN OF PRODUCT ORIENTED MANUFACTURING SYSTEMS
}

\author{
Sílvio Carmo Silva*, Anabela Alves** \\ Universidadedo Minho, (*)scarmo @dps.uminho.pt (**) anabela@dps.uminho.pt
}

\begin{abstract}
A Product Oriented Manufacturing System is designed for the manufacture of a product or a family of similar products. POM may be seen as a development of traditional Cellular Manufacturing and tends to involve more than one cell. A POMS may either be physically organized in a single place or be made of distributed manufacturing or servicing units, thus comprising a virtual system. To be efficient, the POMS design should identify design phases and point to the data, methods and tools that should be used to obtain good design solutions. In this paper, one such methodology is proposed, together with an analysis of the conceptual configuration of the cells that are the building blocks of POM systems.
\end{abstract}

\section{INTRODUCTION}

Cellular Manufacturing Systems (CMS) (Gallagher, 1973), (Burbidge, 1996), (Suresh, 1998) although designed for a variety of parts, grouped into families, rarely take into consideration the need for parts production coordination and synchronization for meeting customer orders of end items. Thus, the need for rapid response to customer requirements, which is recognized as an important strategic objective, is not adequately taken into account. This limitation, however, has been addressed in recent years through a variety of systems interlinking a number of cells. A paradigmatic example of this is what Black calls a linked-cell manufacturing system (Black, 1991). This may be seen as a Product Oriented Manufacturing System (POMS), as may many manufacturing systems currently referred to as JIT, lean, flexible and virtual manufacturing systems (Silva, 2001(a)). POM can also be associated with concepts such as focused factories (Skinner, 1974) and OPIM systems (Putnik, 1995).

To be efficient, POMS should be designed in a way that easily identifies design phases, data, methods and the tools that should be used. This is important for helping the user to obtain good design solutions, taking into consideration all the relevant restrictions.

Here, one such methodology is put forward, together with the definition of a set of conceptual cell configurations seen as building blocks of POM systems. 


\section{PRODUCT ORIENTED MANUFACTURING SYSTEMS}

A POMS is defined as a set of interlinked manufacturing resources and cells that simultaneously and in a coordinated manner address the manufacture of a product or a range of similar products, including the necessary assembly work. A product may be simple, like a part, or complex, having a product manufacturing structure of several levels. This may be represented in a multilevel bill-of-materials. When the product is simple, a POMS may simply take the form of a cell. Otherwise, it comprises a coordinated set of interlinked resources and cells. The coordination of work between manufacturing cells, towards production of end items, is one of the most distinguishing aspect of POMS. A set of cells that does not work under such a coordination setting does not form a POMS.

POM may be seen as a development of traditional Cellular Manufacturing in the sense that a set of interrelated manufacturing cells may be necessary to completely manufacture a product, or a set of similar products, including assembly.

The Design of POMS needs to take logistic operations into account. This is particularly critical when manufacturing resources are distributed in space.

Directing systems to the manufacture of specific products can provide competitive advantages that include short production times and improved product quality. This may be enhanced through the application of recent technical and technological advances in the internal and external logistics of production. In this sense, several strategies to the control of materials, based on the pull and push paradigms, or combinations of these, can be used.

To be successful, POM must be able to fully and dynamically use resources and services available to a company over time, locally or globally, whether they be the company's own or those available in the market. Under changing product demands, frequent, i.e. dynamic, reconfiguration of POMSs will probably be necessary. This is particularly so because POMSs are dedicated to a specific mix of products which, changing over time, calls for new arrangements of resources and services to ensure high levels of operational and economical performance.

A POMS may be built by putting together, in a localized site, manufacturing resources or cells that may be physically dispersed or, alternatively, by organizing them into virtual POMS. Today these can benefit from intranet and internet based technologies, a prerequisite of the widely discussed Virtual Enterprise concept (Camarinha-Matos, 1999). This approach to the virtual configuration of manufacturing systems was initially put forward in 1982, by McLean, Bloom and Hopp (McLean, 1987) (Drolet, 1996) and also by Simpson, Hocken and Albus, according to Ratchev (2001).

POMS are very different from Functional Oriented Manufacturing Systems (FOMS). These are organized in functional departments and are normally oriented towards providing servicing functions for a whole set of different parts and end items with varying processing requirements.

Due to the product oriented nature of POMS, in relation to FOMS, not only can higher productivity, lower WIP, lower throughput time and better production control be expected, but also higher volumes of production. 


\section{DESIGN METHODOLOGY FOR POMS}

Here we propose a methodology for POMS design, identified as the GCD methodology. It is composed of three design phases or functions, namely the Generic, the Conceptual and the Detailed, Figure 1. The methodology is presented in this paper with the support of the IDEF0 modeling technique (FIPS, 1993).

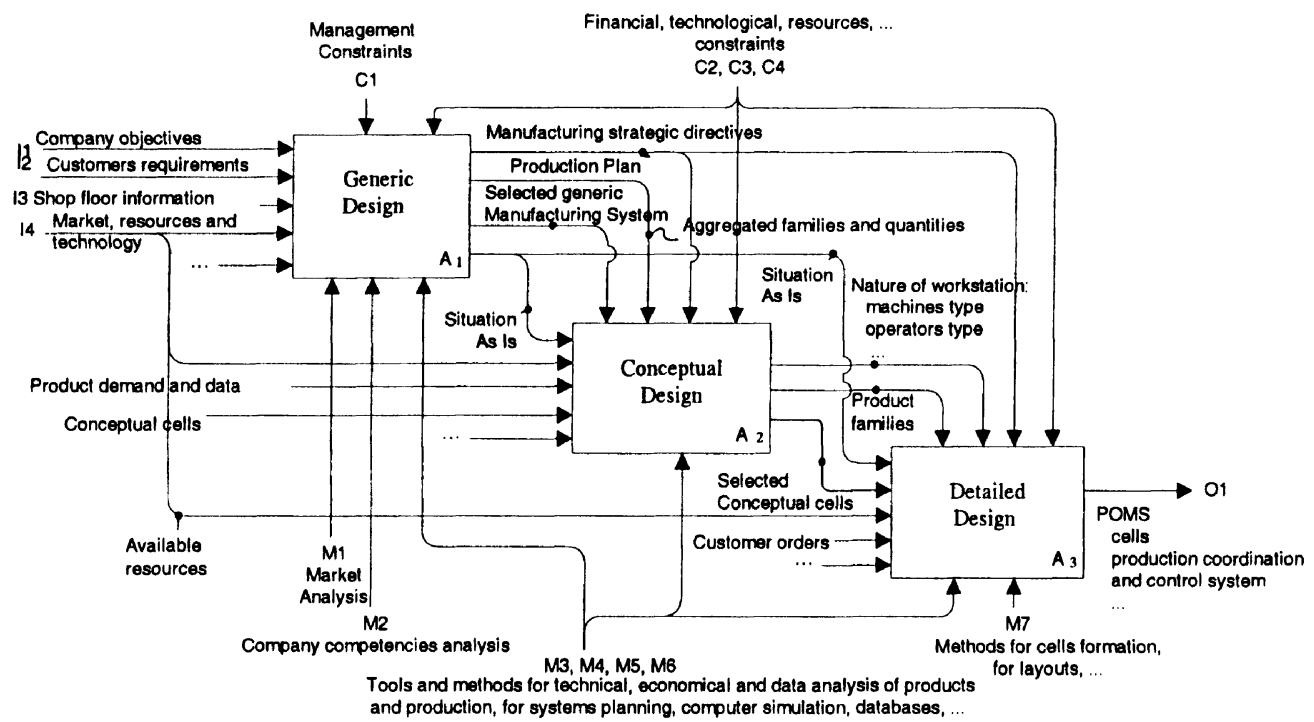

Figure 1 - Overview of the GCD design methodology for POMS

In the GCD methodology, we seek to use all relevant data, restrictions, tools and methods, and to provide for the expandable and up-dated databases and knowledge bases that are relevant to the POMS design. This is in line with design approach of Suh (1995).

Several decisions at strategic, tactical and operational level are used both successively and iteratively in the design process aimed at reaching suitable POMS organizational and operational configurations.

\subsection{Generic Design}

One important decision to be taken at this design phase is to choose the generic manufacturing system configuration. We can identify two extreme and fundamentally different types of generic configurations: the POM configuration and the FOM configuration (Silva, 2002). A third one must be considered, namely the hybrid configuration, which integrates the FOM organization, usually at parts and possibly at some subassemblies manufacturing, and the POM organization. Although we think that efforts must be made to reach pure POMS whenever possible, the hybrid configuration should be considered in the design and decision process. If the FOM configuration is to be used, the GCD methodology's design purpose terminates here. On the other hand, if POM or hybrid arrangements are to be investigated, then the next steps of the methodology should follow.

When we consider using frequent systems reconfiguration for adapting to changing market demands and product manufacturing requirements then, the POM organization is, most probably, very suitable. This is what happens, for example, in 
virtual manufacturing systems. By definition, these are ephemeral systems oriented and designed for addressing a single business opportunity. They are usually identified as a product or a service and, therefore, product oriented.

Another important piece of information generated at the Generic design stage is a production plan. This is essential for developing the subsequent design activities.

Strategic directives must also be given in relation with the sources of manufacturing resources, keeping in mind that a network of cooperating manufacturing units, cells or partners may be involved.

The choices at this design phase are determined by many factors related with company's manufacturing strategy. Particularly relevant are the production requirements resulting from the product forecasted demand, market available resources and services and company present manufacturing position and situation. Product variety and volumes of production should also be identified and a first level analysis of similarities, leading to aggregated product families, should be made.

Thus, we can identify three interrelated design activities at the Generic design phase: Strategic Production Planning (A11), Analysis of Company and Market Manufacturing Situation (A12) and Generic Manufacturing System Selection (A13).

In order to carry out this design phase a variety of tools and methods for technical, economical and data analysis of products and production are required. Examples of these include, clustering methods, $A B C$ analysis, multi-attributes decision analysis (Canada, 1989) and computer simulation.

A more detailed description of this design phase can be seen in Silva (2001(b)).

\subsection{Conceptual Design}

The main and fundamental purpose of this design is selecting conceptual cell configurations that, once implemented in practice, will lead to real POMS configurations. Additionally, a first approximation to product and part families' formation, based on both forecasted and settled customer orders and process plans, must be made. It is also important to specify the nature of workstations and operators. Based on such purposes two main activities must be carried out, namely, Conceptual Cell Configurations Selection (A21) and Workstation Selection (A22), see Figure 2. Clearly matters such as workstation functions/flexibility and operators skills must be defined at this stage.

The conceptual cells that can be used are the basic ones, shown in Figure 3, and their shared cell counterparts, called non-basic (Silva, 2002). These are cells that need to do work on products or parts initially allocated to other cells, or need work to be done in other cells, or both. The adoption of non-basic cells leads to intercellular workflows. The virtual version of conceptual cells should also be considered at this design phase.

Workstations can have a variety of configurations dependent on resource combination and flexibility. Thus the type and quantity of manufacturing resources, such as machines, auxiliary resources, operators and tools, change the nature of workstations. This leads to different versions of each identified conceptual cell, posing different problems for both the design and operation of the POM systems. The following versions of each conceptual cell can be identified (Silva, 2002): flexible conceptual cell, multiprocessor task conceptual cell and multifunction processor conceptual cell for workstations with parallel processors, with multiple 
resources or processors and with multifunction processors respectively. This classification is derived and adapted from the theory of scheduling (Brucker, 1995), (Blazewicz, 1996), (Pinedo, 1995). In practice we might expect to see other versions of conceptual cells, which might combine different types of workstation configurations.

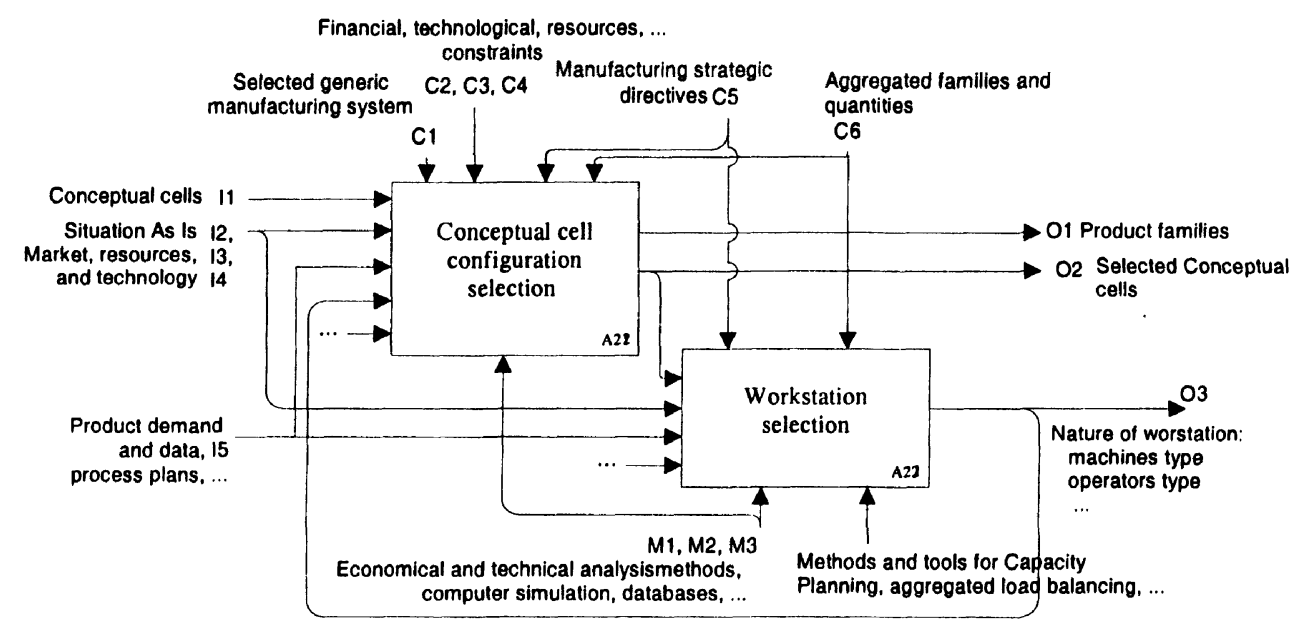

Figure 2 -Conceptual design activities
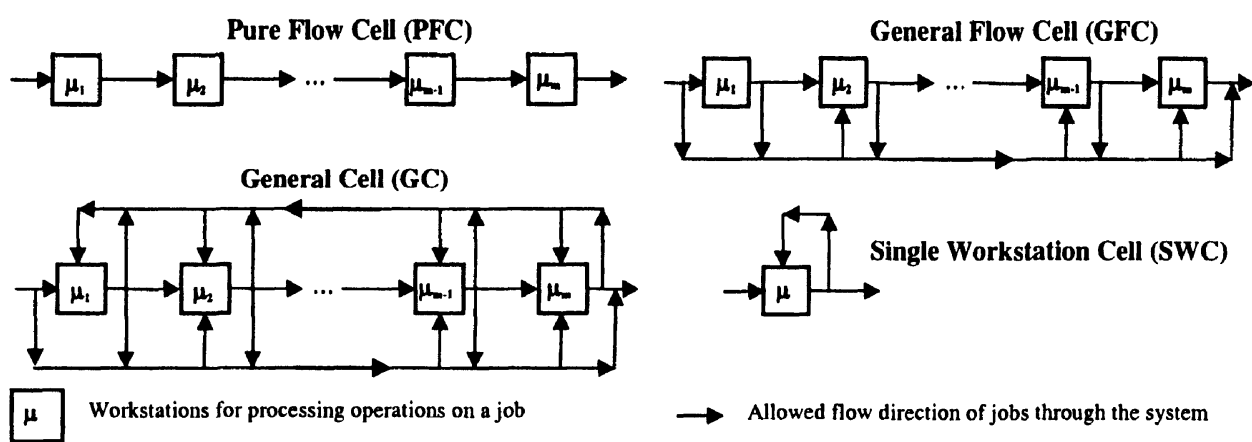

Figure 3 - Schematic representation of the four basic conceptual cell configurations

A typical analysis to be done at this design stage includes workflow analysis associated with the products and processes, which is essential for choosing system configuration based on conceptual cells. This choice requires evaluation of alternatives, which can initially be made through computer simulation.

A range of input data, restrictions and mechanisms for obtaining and evaluating solutions must be used at conceptual design stage as shown in Figure 2.

Important restrictions, information and guidelines are provided by the previous design phase. These include a production plan based on manufacturing aggregated families and guidelines for production capacity mix which take into consideration the company's actual manufacturing position and its strategy for accessing and involving market resources and partners. Decisions in relation to shifts, overtime, outsourcing and make or buy decisions must be put forward too. 
Tools that may be used in this design phase, in addition to database systems and computer simulation, include methods for economical analysis, multi-attributes technical analysis (Canada, 1989), capacity planning and aggregated load balancing.

The results from this design are already a good approximation to the POM system for the product or the family of products selected. However, the real, detailed system configuration is obtained at the next design phase, i. e. at Detailed design.

\subsection{Detailed Design}

The design of POM systems is a dynamic activity at all levels. However, it is at this detailed design level that frequency of design is high. This design should be made every time a new product order is released for production. This order may join together a few customer orders of the same product or of similar products.

At the Detailed design, instantiation of conceptual cells is made, that take into consideration forecasted and customer orders for products. Thus, families of parts, subassemblies and end items, based on actual orders and due dates, are allocated to each conceptual cell and coordinated control of work among cells for POM is devised. Therefore, detailed specification of the production system is achieved, including the design of its physical or virtual configuration.

We identify the following activities at Detailed design phase: Formation of Families of Parts, Subassemblies and End Items (A31), Instantiation of the Conceptual Cells (A32), Instantiation of Workstations (A33), Intracellular Organization and Control (A34) and POM System Organization and Intercellular workflow Coordination and Control (A35).

Activity A31 has to do with manufacturing requirements for the near future. It must deal with an in depth analysis of processing requirements based on actual production orders and existing sources of manufacturing capacity or services, either inside or outside the company. This activity is simplified due to the first level clustering analysis of production previously done at conceptual design stage.

Activity A32 performs the detailed design leading to the manufacturing cells to be implemented in practice. Thus, the allocation of parts to cells and cell configuration is established. This is based on the conceptual cells selected at the previous design phase and on results from the previous design activity. Manufacturing service providers and materials suppliers should also be considered, in design process, at this stage. This is particularly necessary for large and multi site POM systems.

The number of workstations and their manufacturing resources, together with a detailed arrangement of each, is established by activity A33. This involves a detailed knowledge of the main and auxiliary, pieces of equipment available, not only for processing but also for handling, transport and storage. Operators should also be selected, based on skills and on cell operating modes. Activity A33 makes, therefore, the necessary adjustments to the workstations selected at the conceptual level, having in consideration existing manufacturing resources and results of detailed load balancing and of previous Detailed design activities.

Although the conceptual configuration chosen restricts cell arrangements that can be made, there is still a need to clearly define the detailed, intracellular organization and control, achieved by activity A34. This involves the precise location of workstations, machines and auxiliary devices, including workstation 
decouplers (Black, 1995). A clear definition of how materials flow and how operators work within a cell is also required, it being possible to evaluate several layout configurations (Arvindh, 1994), such as the well known U shaped one, which should fit into the conceptual configuration chosen. Moreover, operating cell modes exploring strategies such as teamwork and time-sharing resources (Suri, 1998), rabbit chase, TSS and working balance (Black, 1995), should be considered for implementation.

Finally the POM system can be attained. This culminates with the activity A35 dealing with the total system integration and organization. An important part of this is the selection of the POM intercellular coordination and production control system. This should focus on the need to coordinate and synchronize production of the several items required by each specific product order. This coordination and control system should explore the push and pull paradigms and novel combinations of them such as the POLCA (Suri, 1998), the DBR (Goldratt, 1986), the CONWIP (Spearman, 1990) and SYNCRO-MRP (Hall, 1981) systems, to mention only a few.

It is very clear that, once again, no single design activity can be performed in isolation. All these five-detailed activities are closely interrelated and must be developed in an iterative manner. Moreover, in order to carry them out, a range of methods and tools should be used for technical and economical evaluation of alternative solutions. This means solving problems such as those of detailed clustering of work, equipment selection, intra and intercellular workflow and workload analysis, system flexibility and operations scheduling.

Most probably, detailed computer simulation can be of great use at this design stage. This would certainly help fine tune the resources required including machines, operators and tooling, the evaluation of operating strategies and establishing work schedules.

\section{CONCLUSION}

To keep up with the increasing and ever-changing market demands of today and tomorrow, companies must be able to efficiently manufacture and quickly deliver good quality products to customers. To achieve this, manufacturing companies cannot rely on traditional organization and the operation of systems based on functional departments. Moreover, cellular manufacturing based on uncoordinated or loosely coordinated manufacturing cells is also inappropriate. Present requirements indicate that a more holistic approach to manufacturing is necessary. This can be achieved through Product Oriented Manufacturing Systems (POMS) dynamically built from cells or manufacturing resources, locally or globally available. These must be interlinked and closely coordinated for the total and rapid production of complete products, not parts only. These products may preferably bear manufacturing similarities. Although a localized, physical set-up for such purpose should be sought, POMS are likely to be more dependent on virtual reconfiguration when resources are dispersed or are uneconomical to rearrange.

Designing POM systems is a complex task that requires a methodology that both takes into account the different steps in the design process and points to updated restrictions, data, tools and methods that should be used in the design. The summarized methodology presented in this paper is a contribution to this, 
emphasizing the interrelated and iterative nature of POMS design functions. We call it the GDC methodology because of its three main design phases addressing respectively the Generic, the Conceptual and the Detailed design. We suggest that Conceptual design should concentrate as much as possible on conceptual cells, which may be seen as classes of the different cell configurations, based on complexity of workflow that we may encounter in practice.

\section{REFERENCES}

1. Arvindh B, Irani SA. Cell formation: the need for an integrated solution of the problems. Int. Journal of Production Research, 1994; 32; 5: 1197-218.

2. Black JT, Chen JC. The role of decouplers in JIT pull apparel cells. International Journal of Operations \& Production Management, 1995; 7, 1: 17-35.

3. Black JT. The Design of the Factory with Future. McGraw-Hill, Inc., 1991

4. Blazewicz J, Ecker KH, Pesch E, Schmidt G, Weglarz J. Scheduling Computer and Manufacturing Processes. Springer Verlag, Heidelberg, 1996.

5. Brucker, P. Scheduling Algorithms. Springer, 1995.

6. Burbidge JL. Production Flow Analysis for Planning Group Technology. Clarendon Press, 1996.

7. Camarinha-Matos LM, Afsarmanesh H. "The Virtual Enterprise Concept". In Working Conference on Infraestructures for Virtual Enterprises (PRO-VE'99), L. M. Camarinha-Matos and H. Afsarmanesh, ed., Kluwer Academic Publishers, 1999.

8. Canada JR, Sullivan WG. Economic and multiattribute evaluation of Advanced Manufacturing Systems. Prentice-Halll, 1989.

9. Drolet JR, Montreuil B, Moodie CL. Empirical Investigation of Virtual Cellular Manufacturing System. Symposium of Industrial Engineering - SIE'96, 1996.

10. FIPS PUBS - Federal Information Processing Standards Publications. Draft FIPS Publication 183 Announcing the standard for Integration Definition for Function Modeling (IDEF0). http://www.sdct.itl.nist.gov/ ftp/idef/idef0.rtf, 1993.

11. Gallagher CC, Knight WA. Group Technology. Butterworths, 1973.

12. Goldratt EM, Fox RE. The Race, North River Press, Inc, 1986.

13. Hall, RW. "Syncro MRP: Combining Kanban and MRP - The Yamaha PYMAC System" In Driving the Productivity Machine: Production Planning and Control in Japan, APICS, 1981: 43-56.

14. McLean CR, Brown, PF. "The Automated Manufacturing Research Facility at the National Bureau of Standards". In New Technologies for Production Management systems, H. Yoshikawa e J. L. Burbidge, ed., Elsevier Science Publishers B. V. North - Holland, 1987.

15. Pinedo, M. Scheduling - Theory, Algorithms and Systems. New Jersey: Prentice-Hall Inc, 1995.

16. Putnik GD, Silva SC. "One Product Integrated Manufacturing". In Balanced Automation Systems, L. M. Camarinha-Matos, H. Afsarmanesh, eds. Chapman \& Hall, 1995.

17. Ratchev, SM. Concurrent process and facility prototyping for formation of virtual manufacturing cells. Integrated Manufacturing Systems, 2001; 12: 4, 306-315.

18. Silva SC., Alves, AC. SPOP - Sistemas de Produção Orientados ao Produto. Células Autónomas de Produção - TeamWork' 2001 Conferencia, Lisboa, 2001 (a).

19. Silva SC, Alves AC. Uma Metodologia para o Projecto de Sistemas de Produção Orientados ao Produto. VII Int. Conf. on Industrial Engineering and Operations Management, Brasil, 2001 (b).

20. Silva SC., Alves, AC. A Framework for Understanding Cellular Manufacturing, accepted to CAR\&FOF Conference, Porto, Portugal, 2002.

21. Skinner, W. The focused factory. Harvard Business Review, 1974.

22. Spearman ML., Woodruff DL, Hopp, WJ. CONWIP: A Pull Alternative to Kanban, International Journal of Production Research, Vol. 28, N. 5, 879-894, 1990.

23. Suresh NC, Kay JM. Group Technology and Cellular Manufacturing - State of the Art Synthesis of Research and Practice. Kluwer Academic Publishers, 1998.

24. Suri, R. Quick Response Manufacturing - A Companywide Approach to Reducing Lead Times. Oregon: Productivity Press, 1998.

25. Suh NP. Design and Operation of Large systems. Journal of Manufacturing Systems, 1995; 14; 3 : 203-13. 